\title{
Pathological and Ultrastructural Characteristics of Newcastle and Pox Diseases in Naturally Infected Pigeons in Egypt
}

\author{
Shady M. Shalaby ${ }^{1 *}$, Walaa F. Awadin ${ }^{1}$, Mohamed F. Hamed ${ }^{1}$, Mohamed El-Tholoth ${ }^{2}$, Iman \\ Ibrahim ${ }^{1}$, Ahmed F. EL- ShaIEB ${ }^{1}$
}

${ }^{1}$ Department of Pathology, Faculty of Veterinary Medicine, Mansoura University, Egypt; ${ }^{2}$ Department of Virology, Faculty of Veterinary Medicine, Mansoura University, Mansoura 35516, Egypt.

\begin{abstract}
During 2019-2021, a total of 456 and 320 pigeons showed clinical signs suspected to be infected with Newcastle disease (ND) and pox disease (PD), respectively at El Gharbia and El Dakahlia Provinces causing several losses to pigeons fanciers despite of culling and vaccination strategies. Confirmative diagnosis of infections was carried out by the molecular detection of both viruses by quantitative real time-polymerase chain reaction (qPCR). Histopathological examination, immunohistochemistry (IHC) staining and transmission electron microscopy (TEM) were conducted on PCR positive specimens. Histopathologically, meningoencephalitis, tracheitis, necrotizing pneumonia, tubulointerstitial nephritis and hyperplasia of gut associated lymphoid tissue were seen in pigeons infected with NDV. Meanwhile hypertrophy and hyperplasia of epidermal stratified squamous epithelium with dense eosinophilic intracytoplasmic inclusion bodies (ICIB) were observed in PD infected pigeons. IHC showed immunopositive staining for Newcastle disease virus (NDV) in brain, lung, heart, intestine, liver, and kidney while immunopositive avipoxviral staining were seen in epidermis and dermis. TEM of infected brain tissue with NDV showed hypertrophied neuron with numerous electron dense granules, dilated mitochondria, and rough endoplasmic reticulum. Intracytoplasmic and intranuclear electron dense inclusion bodies and degenerated axon were also seen. TEM of infected epidermal cells with avipoxvirus showed swollen cells with intracytoplasmic electron lucent inclusion bodies containing cellular debris. In conclusion, this study presented histopathological, immunohistochemical and ultrastructural changes in pigeons molecularly confirmed to be naturally infected with ND and PD.
\end{abstract}

Keywords | Newcastle disease virus, Pox disease virus, Pigeons, Histopathology, Immunohistochemistry, Transmission electron microscopy

Received | June 29, 2021; Accepted | August 04, 2021; Published | October 01, 2021

*Correspondence | Shady M. Shalaby, Department of Pathology, Faculty of Veterinary Medicine, Mansoura University, Egypt; Email: shadyshalaby25@gmail. com

Citation | Shalaby SM, Awadin WF, Hamed MF, El-Tholoth M, Ibrahim I, El-Shaieb AF (2021). Pathological and ultrastructural characteristics of Newcastle and pox diseases in naturally infected pigeons in Egypt. Adv. Anim. Vet. Sci. 9(11): 1995-2004.

DOI | http://dx.doi.org/10.17582/journal.aavs/2021/9.11.1995.2004

ISSN (Online) | 2307-8316; ISSN (Print) | 2309-3331

Copyright (c) 2021 Shalaby et al. This is an open access article distributed under the Creative Commons Attribution License, which permits unrestricted use, distribution, and reproduction in any medium, provided the original work is properly cited.

\section{INTRODUCTION}

$\mathrm{N}$ ewcastle disease (ND) is a viral disease affecting over 240 species of birds including pigeons, it considered the most important disease affecting pigeons (Bulbule et al., 2015). It caused by Genotype VI Newcastle disease virus (NDV) called pigeon paramyxovirus type 1 (PPMV1) (Xue et al., 2017) that is closely related but not identical to paramyxoviruses causing ND in poultry (Alexander et al., 1985). The virus could replicate in various tissue but the most affected organ was the brain (Liu et al., 2015) and the neurological symptoms could be attributed to the intense inflammatory responses induced by PPMV-1 in the brain of infected pigeons (Xiang et al., 2019). Pigeons infected with PPMV-1 showed high morbidity and high mortality (Xiang et al., 2019) that reach to $80 \%$ and $70 \%$, respectively (Dortmans et al., 2010; Guo et al., 2014). Pigeons suffered from greenish diarrhea which could be 
profuse and hemorrhagic (Dolka et al., 2019; Vindevogel et al., 1972). Neurological signs were characteristic and included torticollis, neck tremors and unilateral paralysis leading to unbalanced gait or staggering and unbalanced flight (Marlier and Vindevogel, 2006; Dortmans et al., 2010; Guo et al., 2014; Coudert and Donas, 2015; Dolka et al., 2019; Eisa and Omer, 1984). Some pigeons suffered from eye lesions led to vision disturbance (Dortmans et al., 2010; Guo et al., 2014). Other symptoms include depression, weight loss and ruffled feathers (Dortmans et al., 2010; Guo et al., 2014; Xiang et al., 2019). Some cases showed persistent diarrhea without nervous manifestations (Marlier and Vindevogel, 2006).

Pox disease (PD) is a viral disease caused by Pigeon pox virus (PPV) within genus Avipoxvirus in the family Poxviridae (Fenner, 2000). PD could be transmitted by bites of arthropods, inhalation of aerosols from infected birds or ingestion of contaminated food and water. PPV enters the body through skin wound or through the mucous membrane and cause localized infection at point of entry, then it may spread by blood to liver and bone marrow causing systemic infection (Doneley, 2006). PD occurred in two forms cutaneous form (dry form) and diphtheric form (moist form). Both cutaneous and diphtheric form could occur together in the same bird that appeared as greyish white nodules scattered around eye, legs and skin with yellowish nodules on the mucosa of mouth, pharynx and larynx (Jan et al., 2017).

In cutaneous form, lesions found mainly around the eye, on skin, beak, and around cloaca and appeared as greyish white nodules(Immannietal.,2014; Sudhakara and Sivajothi,2017; Audarya et al., 2018) and characterized by multiple masses or nodules were found on beak, mouth and eyelid. Those nodules were round, firm, rough, yellowish and of $0.5-1 \mathrm{~cm}$ in diameter then the nodules formed wart like scab and the superficial lesions were ulcerated. The affected pigeons were emaciated and dehydrated (Docherty et al., 1991; Gülbahar et al., 2005; Mohan and Fernandez, 2008). The moist form of pox found on mucus membranes of upper digestive tract (mouth, tongue, and esophagus) and upper respiratory tract. The lesions appeared as yellow proliferative and fibronecrotic which interfered with eating and drinking leading to emaciation and dehydration (Tripathy and Reed, 2003).

The study was designed to add as much information about pathological changes associated with the circulating ND and PD in pigeons at E1-Gharbia and El-Dakahlia Provinces during the period from 2019 to 2021.

\section{MATERIALS AND METHODS}

\section{SAMPLE SOURCE}

During the period 2019 to 2021, pigeons at E1 Gharbia and
El Dakahlia Provinces showed skin lesions or neurological signs, greenish diarrhea, respiratory signs, conjunctivitis, and death were collected and submitted to Department of Pathology, Faculty of Veterinary Medicine, Mansoura University.

\section{Tissue SAMPLING}

Following clinical examination, diseased pigeons were euthanized. Recently dead and diseased pigeons were necropsied. Clinical signs and postmortem findings were reported. Tissue specimens were taken in case of PD from skin, liver, lungs. In cases suspected to be infected with $\mathrm{ND}$, tissue specimens were collected from trachea, lungs, liver, intestine, and brain. All collected specimens from each examined pigeon were labelled and fixed separately in $10 \%$ formalin at room temperature for $12: 48 \mathrm{hrs}$. for histopathology and IHC. Representative samples were collected from skin in case of PD, cerebral hemispheres in case of nervous manifestation then frozen at $-20{ }^{\circ} \mathrm{C}$ until time of nucleic acid extraction. Samples for electron microscope (skin in case of PD, brain in case of nervous manifestation) were immediately fixed in $2.5 \%$ buffered glutaraldehyde $+2 \%$ paraformaldehyde in $0.1 \mathrm{M}$ sodium phosphate buffer $\mathrm{pH} 7.4$ and left overnight at $4^{\circ} \mathrm{C}$. Negative control samples from healthy chicken were also collected.

\section{Nucleic ACIDS EXTRACTION FOR NDV AND PV}

Extraction of nucleic acids from collected samples was done by AM1836 5X MagMax 96 Viral Extraction kit (Life Technologies Corp.) according to the manufacture protocol.

\section{REAL TIME- R'T- PCR (R'T-QPCR)}

The RNA was amplified using SsoFast EvaGreen Supermix (Bio-Rad) using the matrix (M) gene as a template. Forward primer was (NDV) $\mathrm{M}+4100$ (5' -AGTGATGTGCTCGGACCTTC-3') and reverse primer was M-4220 (5' -CCTGAGGAGAGGCATTTGCTA-3') (Wise et al., 2004). The reagents of RT-qPCR were as mentioned in Table 1 . The used cycling program was as mentioned in Table 2.

Fluorescence emissions due to DNAs amplifications were monitored via the 7500-Fast Real Time PCR system (Applied Biosystems). Non-template controls were involved in each run to ensure no contamination was present.

\section{QPCR FOR PV DETECTION}

The DNA was amplified using SsoFast EvaGreen Supermix (Bio-Rad) using $4 \mathrm{~b}$ core protein gene of pox virus as a template. forward primer was (ACGTCAACTCATGACTGGCAAT) and reverse primer was (TCTCATAACTCGAATAAGATCTTGTATCG) 
(Baek et al., 2020). The reagents of QPCR were as mentioned in Table 3. The used cycling program was as mentioned in Table 4.

Fluorescence emissions due to DNAs amplifications were monitored via the 7500-Fast Real Time PCR system (Applied Biosystems). Non-template controls were involved in each run to ensure no contamination was present.

\section{Histopathology AND IMMUNOHISTOCHEMisTRY}

Trimming of PCR- positive tissue samples were done under fume hood to fit into cassettes and labeled. Tissue samples were dehydrated in ascending grades of ethanol, cleared in xylene, and embedded in melted paraffin. Two set of paraffin sections of 4-5 $\mu \mathrm{m}$ were cut using microtome then placed on clean glass slides. The first set was dewaxed in xylene and rehydrated in descending grades of ethanol then stained with hematoxylin and eosin (HE) according to (Slaoui and Fiette, 2011). The second set was immunostained to identify expression of viral antigen by EnVision method on different tissues according to Kim et al. (2016) and Suvarna and Layton (2013). Briefly, sections were deparaffinized in xylene, then rehydrated in gradual descending concentrations of ethanol followed by phosphate buffer saline (PBS) ( $\mathrm{pH}$ 7.4). Antigen retrieval was done by autoclaving at $120^{\circ} \mathrm{C}$ for $20 \mathrm{~min}$ then washed three times by PBS. The endogenous peroxidase activity was blocked with $3 \%$ hydrogen peroxide $\left(\mathrm{H}_{2} \mathrm{O}_{2}\right)$ for $5 \mathrm{~min}$ at room temperature. After rinsing with $\mathrm{PBS}$ ( $\mathrm{pH} 7.4$ ), tissue sections were incubated with primary antibodies (for NDV: Anti-NDV prepared in chicken for pox: antipox prepared in chicken diluted by 1:100 in Ab diluting buffer) prepared in Virology Department, Animal Health Research Institute, Dokki and incubated at $4^{\circ} \mathrm{C}$ overnight. After triple washing with PBS, the slides were incubated with an anti-chicken secondary antibody (1:200) for $1 \mathrm{hr}$ at room temperature, followed by washing and development of antigen-antibody visualization with $0.04 \%$ 3, 3'-diaminobenzidine tetrahydrochloride (DAB) (20 ul in $1 \mathrm{ml}$ buffer solution) for $1 \mathrm{~min}$. Finally, the sections were washed under tap water and counterstained with Mayer's hematoxylin. The stained sections were covered with glycerol gel and examined by light microscopy.

\section{TRANSMISSION ELECTRON MICROSCOPY (TEM)}

Tissue specimens approximately $1 \mathrm{~mm}^{3}$ from skin in case of PD and brain in case NDV were fixed in $2.5 \%$ buffered glutaraldehyde $+2 \%$ paraformaldehyde in 0.1 $\mathrm{M}$ sodium phosphate buffer $\mathrm{pH}$ 7.4. Sample were rinsed in $0.1 \mathrm{M}$ sodium phosphate buffer + 0.1 M Sucrose then postfixed in $2 \%$ sodium phosphate buffered osmium tetroxide $\mathrm{pH} 7.4$ for $90 \mathrm{~min}$ then dehydration was done through ascending graded ethanol series. Samples were infiltrated with descending graded of Epon: Acetone mixture then embedded in a pure Epon solution overnight at $4^{\circ} \mathrm{C}$ followed by incubation for $\sim 48$ hours at $70^{\circ} \mathrm{C}$ for polymerization. $0.5 \mu \mathrm{m}$ initial sections were cut by ultramicrotome to identify the specific area for ultrathin sections. These sections were stained with toluidine blue then examined under light microscopy. 50-100nm ultrathin sections were made by ultramicrotome (Morris, 1965) then post contrast was done according to Reynolds (1963) in 8 $\%$ uranyl acetate for $10 \mathrm{~min}$. followed by $1 \%$ lead citrate for $5 \mathrm{~min}$. Sections were examined with $160 \mathrm{kV}$ using a JEOL JEM -2100 transmission electron microscopy at EM Unit, Mansoura University, Egypt.

\section{RESULTS AND DISCUSSION}

\section{Clinical Findings AND POSTMORTEM Lesions} REPORTED FOR ND AND PD

During 2019-2021, a total of 456 and 320 pigeons showed clinical signs suspected to be infected with Newcastle disease (ND) and pox disease (PD), respectively at ElGharbia and El-Dakahlia. The age of the pigeons ranged between 15 days and 3 years. When a preliminary diagnosis of NDV (PPMV-1) infection was made, the following signs were observed: torticollis, head tremors and incoordination in all examined cases (Figure 1A), leg and wing paralysis in 50 out of the 456 examined pigeons (10.9\%), respiratory signs in 30 birds (6.5\%), conjunctivitis in 22 birds (4.8\%) and greenish diarrhea in all investigated pigeons. Gross examination upon necropsy showed congestion and/or hemorrhage in meninges, brain tissues, congested and/ or hemorrhagic lungs, congestion and/or hemorrhage in kidney, liver, and intestine.

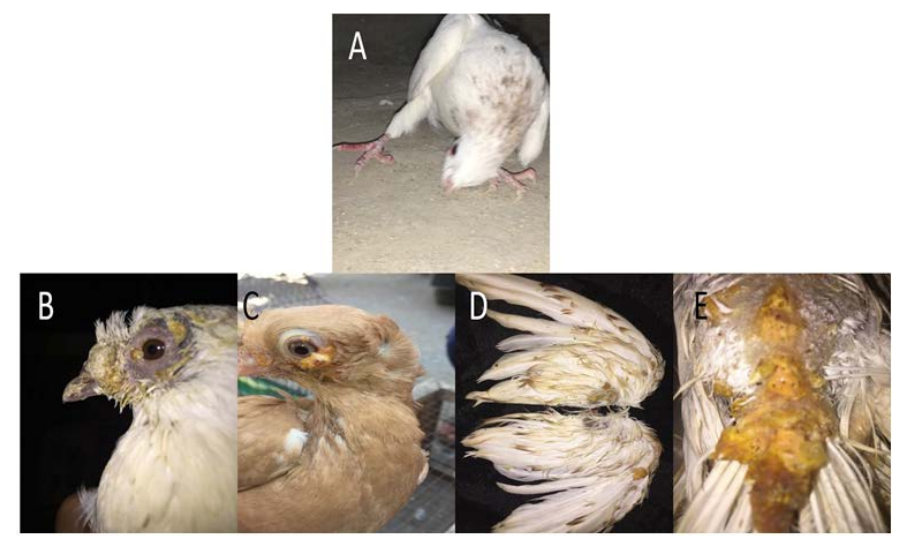

Figure 1: Gross pictures showing torticollis in pigeons infected with ND, (A) In case of PD, multiple yellowish nodules were observed on feathered and unfeathered skin in the head, beak (B), eyes (C), wings (D), back (E).

In case of PD, multiple yellowish nodules were observed on feathered and unfeathered skin mainly around the eyes, cloaca, beak, and legs (Figure 1B-E). Lesions in internal organs were nonspecific. 


\section{PCR FOR NDV AND PD}

$\mathrm{Ct}$ values of extracted nucleic acids showed positive amplification signals for NDV (PPMV-1) (Graph 1) and avipoxvirus (Graph 2) in clinically collected samples from diseased birds. Non template control and negative controls did not show any amplification results.

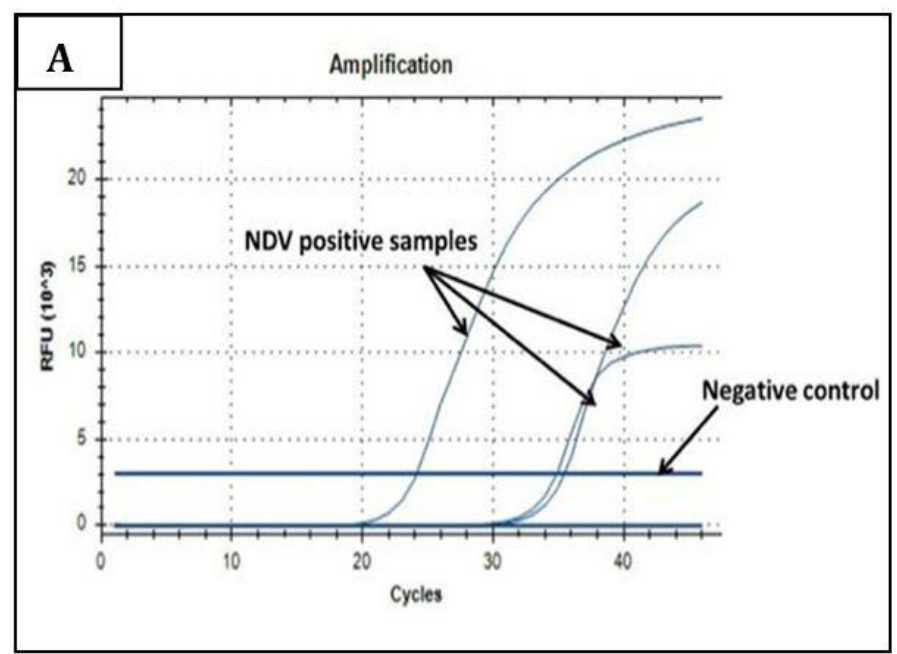

Graph 1: Amplification plot of RT-PCR in NDV molecular detection. Three field samples gave positive amplification with threshold cycles $(\mathrm{Ct})$ ranging from 24-35. The negative control sample gave no amplification signals.

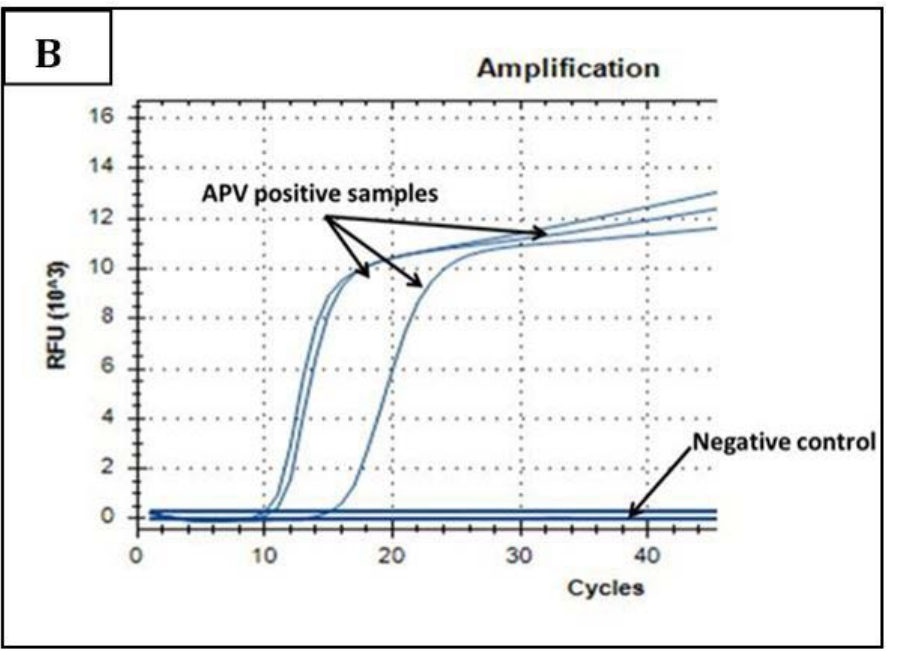

Graph 2: Amplification plot of PCR in PD molecular diagnosis. Three field samples gave positive results with threshold cycles $(\mathrm{Ct})$ ranging from 11-15. The negative control sample gave no amplification signals.

\section{Histopathology AND IHC FINDINGS IN POSITIVELY} INFECTED PIGEONS

Histopathological examination of infected pigeons with ND showed heterophilic infiltrations in tracheal mucosa (Figure 2A), few necrotic cardiomyocytes (Figure 2C), and necrotizing pneumonia (Figure $3 \mathrm{~A}$ ). Additionally, hyperplasia of bronchus associated lymphoid tissue (Figure
3B), meningeal congestion and hemorrhage (Figure 3D) with marked cerebral congestion (Figure 3E) were also observed. Tubulointerstitial nephritis with tubular epithelial degeneration and necrosis beside atrophied
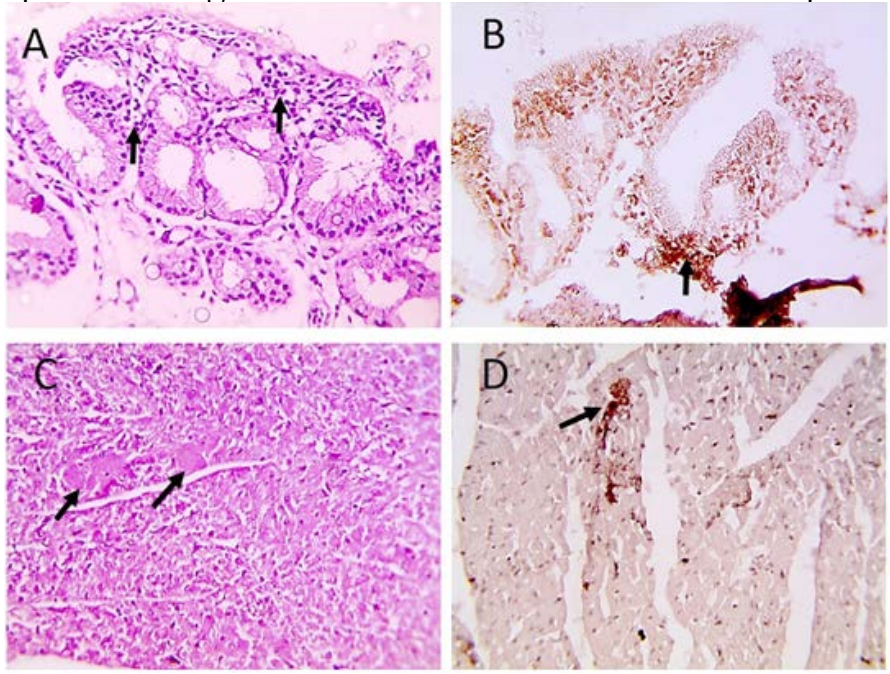

Figure 2: Microscopic pictures of $\mathrm{PCR}$ positive specimens for ND showing heterophilic infiltration in tracheal mucosa (black arrows) (A), few necrotic cardiomyocytes (black arrows) (C), HandE. PPMV-1 viral antigen is positively stained by IHC in tracheal mucosa (black arrows) (B) and in cardiomyocytes (black arrows) (D), IHC counterstained with Mayer's hematoxylin, X: 400.
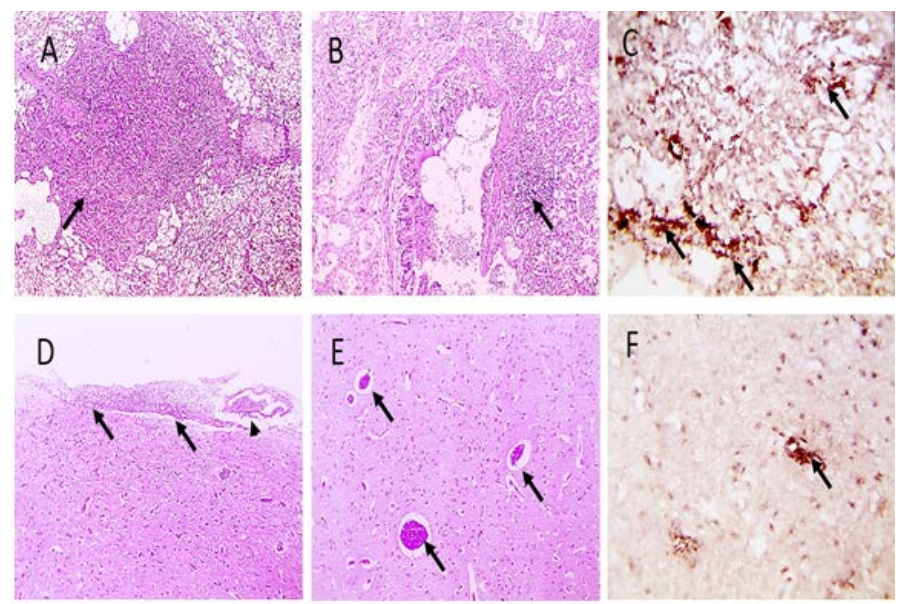

Figure 3: Microscopic pictures of $\mathrm{PCR}$ positive specimens for ND showing necrotizing pneumonia (black arrows) (A) with hyperplasia of bronchus associated lymphoid tissue (black arrows) (B), meningeal congestion (black arrowhead) and hemorrhage (black arrow) (D), marked cerebral congestion (black arrows) (E), HandE. PPMV-1 viral antigen is positively stained by IHC in alveolar wall (black arrows) (C) and in cerebral cortex (black arrows) (F), IHC counterstained with Mayer's hematoxylin, X: 400.

glomeruli were observed (Figure 4A and 4B). Liver showed hepatitis with hepatocellular vacuolar degeneration and necrosis infilterated with high number of macrophages in sinusoids and space of Disse (Figure 4D and 4E). Lymphoid aggregation (hyperplasia of gut associated 
lymphoid tissue) was noticed in duodenal mucosa (Figure 5A). The immunohistochemistry results showed positive immunostained PPMV-1 viral antigen in tracheal mucosa (Figure 2B), cardiomyocytes (Figure 2D), alveolar wall (Figure 3C), cerebral cortex (Figure 3F), interstitial renal tissue (Figure 4C), hepatic sinusoids and space of Disse (Figure 4E) and intestinal epithelial cells and villous lamina propria (Figure 5B and I).

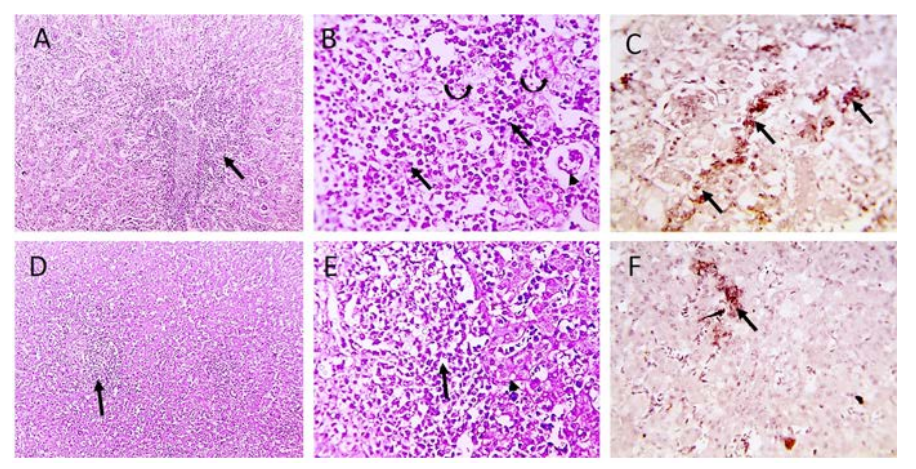

Figure 4: Microscopic pictures of PCR positively infected pigeon with NDV showing tubulointerstitial nephritis (staright black arrows) with tubular epithelial degeneration (curved black arrows), tubular epithelial necrosis (dashed black arrows) and atrophied glomeruli (black arrowheads) (A and B). Hepatitis with hepatocellular vacuolar degeneration (black arrowhead) and necrosis and high number of macrophages in sinusoids and space of Disse (black arrows) (D and E), $\mathrm{H}$ and E.PPMV-1 viral antigen is positively stained by IHC in interstitial renal tissue (black arrows) (C), in hepatic sinusoids and space of Disse (black arrow) (F), IHC counterstained with Mayer's hematoxylin (A, D X:100; B, E, C, F X: 400).

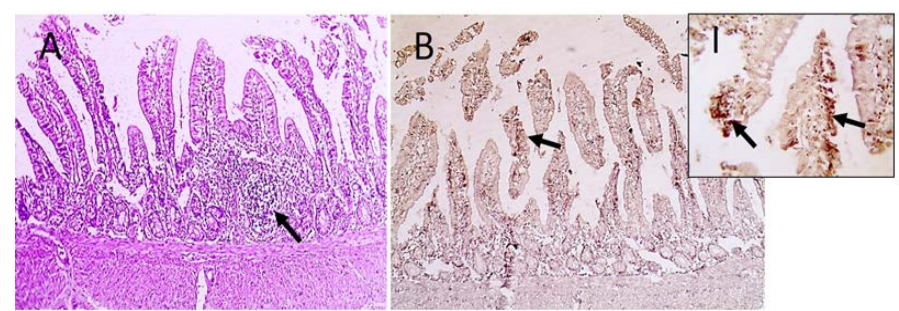

Figure 5: Microscopic pictures of $\mathrm{PCR}$ positive specimens for ND showing lymphoid aggregation (hyperplasia of gut associated lymphoid tissue) was noticed in duodenal mucosa (black arrows) (A), X:400. HandE. PMV-1 viral antigen is positively stained by IHC in intestinal epithelial cells and villous lamina propria (black arrows) (B and I), IHC counterstained with Mayer's hematoxylin, X:100 and insert (I) X: 400.

On the other hand, the histopathological examination of infected pigeons with PD showed epideramal thickening with hyperplasia of stratified squamous epithelium. Diffuse, intense swollen epidermal cells with pale foamy vacuolated cytoplasm and dense eosinophilic intracytoplasmic inclusion bodies (ICIB) were also seen
(Figure 6A and B). Additionally, marked heterophilic and lymphocytic infilterations were observed in superficial and deep dermis (Figure 6C and D). Occasionally, few bacterial colonies were seen in the affected skin. Interstitial nephritis with mononuclear cells (MNC) infiltration admixed with extensive RBCs widely separated a necrotic renal tubule (Figure 7A-C). Furthermore, multifocal areas of hepatic necrosis with heterophilic and lymphocytic perivascular infiltrations were also seen. Interstitial edema with vacuolated cardiac muscle fibers were detected in (Figure $7 \mathrm{G}, \mathrm{H}$ ) and pulmonary congestion (Figure 7I) were detected in heart and lungs sections respectively. Immunohistochemistry examination showed positive immunostained Avipoxvirus viral antigen in epidermal cells and in dermal infiltrating leukocytes (Figure 6E and F).
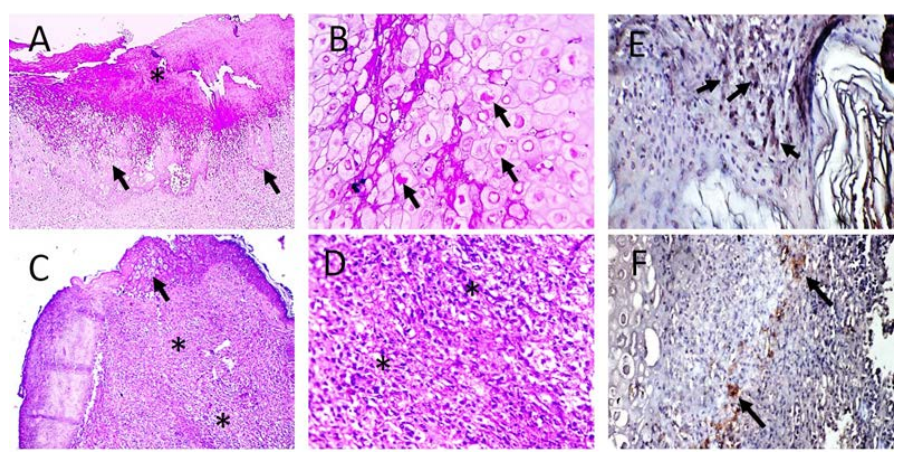

Figure 6: Microscopic pictures of PCR positive skin for PD showing thick keratinaceous and amorphous crust and necrosis (*) (A), hypertrophy and hyperplasia of epidermal stratified squamous epithelium having pale foamy vacuolated cytoplasm and dense eosinophilic ICIB (black arrows) (B), severe heterophils and lymphocytic cells infiltration in superficial and deep dermis $\left(^{*}\right)(C$ and D). HandE (A and C X:100; B and D $\mathrm{X}: 400)$. Avipoxvirus viral antigen is positively stained by IHC in epidermal cells and in dermal infiltrating leukocytes (E and F), IHC counterstained with Mayer's hematoxylin, X: 400.

Thick keratinaceous and amorphous crust and necrosis, hypertrophy and hyperplasia of epidermal stratified squamous epithelium having pale foamy vacuolated cytoplasm and dense eosinophilic intracytoplasmic inclusion bodies (ICIB) (Figure 6A and B), severe heterophils and lymphocytic cells infiltration in superficial and deep dermis (Figure 6C and D). At few places in the affected skin section, few colonies of bacteria were observed. Microscopic examination of kidneys showed congestion, interstitial nephritis characterized by mononuclear cells (MNC) infiltration admixed with RBCs mainly in perivascular space extending to interstitial tissue causing destruction of renal tubules accompanied with tubular necrosis in adjacent parenchyma (Figure 7A-C). Microscopic examination of liver showed multifocal areas 
of necrosis with perivascular infiltration with heterophils and lymphocytes (Figure 7D-F). Microscopic examination of heart showed interstitial edema and vacuolated cardiac muscle fibers (Figure 7G-H) Microscopic examination of lungs revealed congestion (Figure 7I). Avipoxvirus viral antigen was positively stained by IHC in epidermal cells and in dermal infiltrating leukocytes (Figure 6E and F).

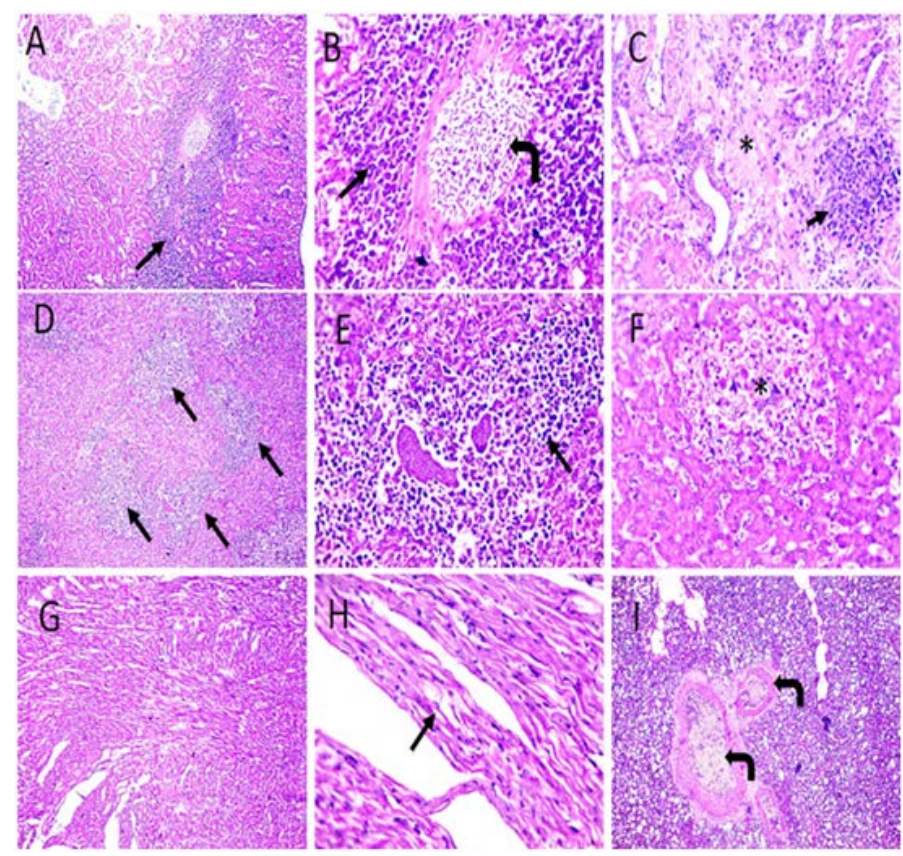

Figure 7: Microscopic pictures of PCR positive specimens for PD showing congestion (right angled black arrows), interstitial nephritis characterized by MNC infiltration admixed with $\mathrm{RBCs}$ mainly in perivascular space extending to interstitial tissue (black arrows) causing destruction of renal tubules accompanied with tubular necrosis in adjacent parenchyma $\left(^{*}\right)$ in kidneys (A-C). Perivascular infiltration with heterophils and lymphocytes (black arrows) with multifocal areas of necrosis $\left(^{*}\right)(\mathrm{D}-\mathrm{F})$. Vacuolation in cardiac muscle fibers (black arrows) ( $\mathrm{G}$ and $\mathrm{H})$. Congestion of pulmonary blood vessels (black arrows) (I). H and E (A, D, G X: 100; others X: 400).

\section{TEM RESULT}

Transmission electron microscopy of brain and skin were done to confirm the histopathological examination of ND and pox disease, respectively. The result of brain showed presence of variable sized globular intracytoplasmic and intranuclear electron dense bodies in neuron, microglia, and other neurological cells. Additionally, hypertrophied neuron with numerous electron dense granules, dilated mitochondria, and rough endoplasmic reticulum beside redundant and degenerated axon with loss of myelin sheath were also detected (Figures 8, 9).

The infected skin of pox disease showed swollen skin cells with large, homogenous intracytoplasmic electron lucent bodies containing cellular debris. Others showing large clear intracytoplasmic bodies compressing nucleus peripherally. Additionally, there were other cells with chromatin condensation, loss of cytoplasmic organelles and loss of intercellular adhesion (Figure 10).
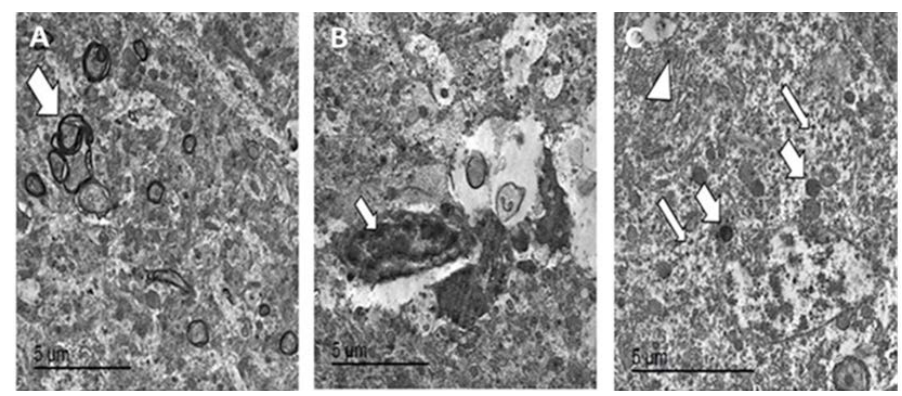

Figure 8: TEM micrographs from brain of PCR positively infected pigeon with NDV showing redundant axon (white arrow) (A), intranuclear electron dense inclusion body intranuclear electron dense inclusion body (white arrow) (B), hypertrophied neuron showing numerous electron dense granules clumping (thin white arrows), dilated mitochondria (thick white arrows) and dilated RER (white arrowhead) (C), bar $=5 \mu \mathrm{m}$.
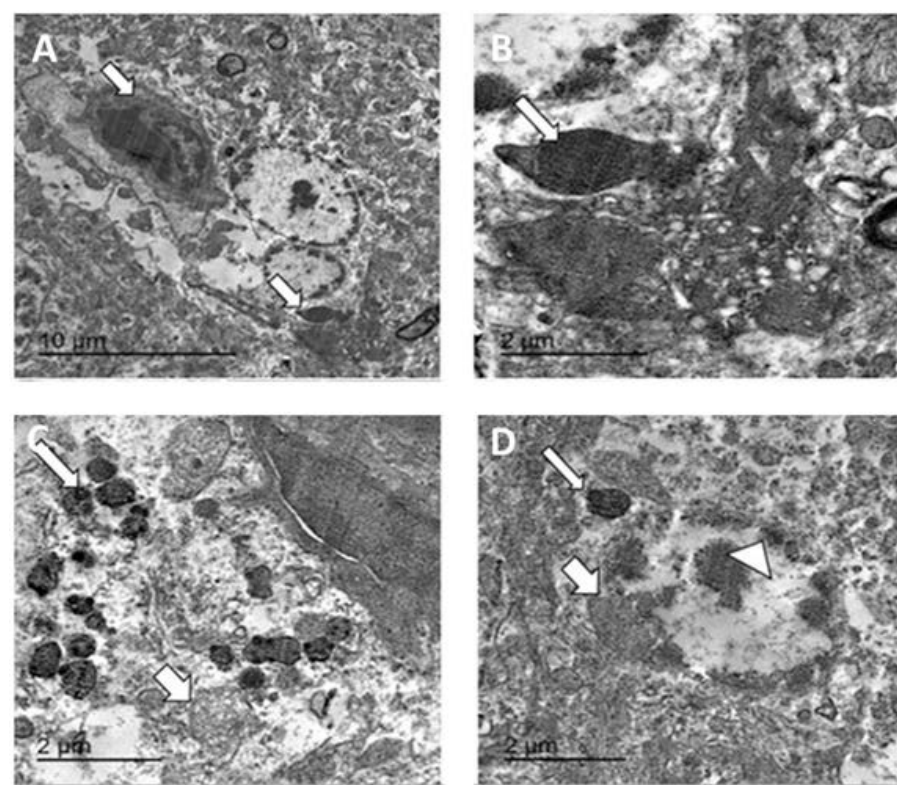

Figure 9: TEM micrographs from brain of infected pigeon with NDV showing neuron having intracytoplasmic electron dense inclusion bodies containing nucleocapsid (white arrow) (A) Bar=10 $\mu \mathrm{m}$, high magnification of neuron showing large globular electron dense intracytoplasmic

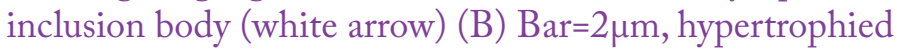
neuron with numerous intracytoplasmic globular electron dense inclusion bodies (thin arrow) with marked mitochondrial dilation (thick arrow) (C) Bar $2 \mu \mathrm{m}$, hypertrophied neuron with dilated mitochondria (thick arrow), intracytoplasmic (thin arrow) and intranuclear electron dense inclusion bodies (arrowhead) (D) bar $=2$ $\mu \mathrm{m}$.

The present study conducted from 2019 to 2021 in El- 
Gharbia and El-Dakahlia provinces in an attempt to determine the most important viruses affecting pigeons, although the study didn't cover the exact population in those area due to the nature of the rearing of pigeons as the pigeon fanciers always let the birds fly and come back so the population in one loft is continuously changing due to the loses from flight and the migration of foreign birds so the study represent an average number to the affected pigeons.
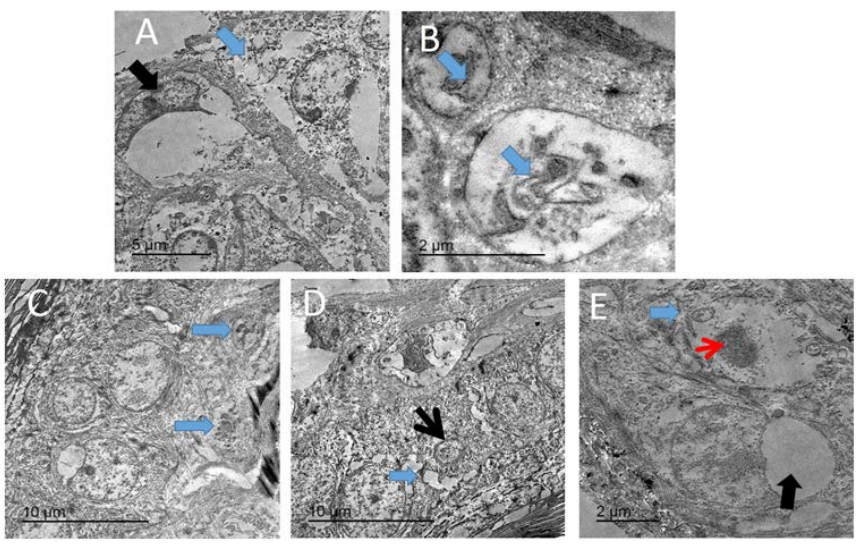

Figure 10: TEM micrograph of skin of PCR positively infected pigeon with PD showing swollen cells with damaged cytoplasmicorganelles, nuclear membrane rupture (blue arrow) and compressed nucleus with electron lucent homogenous materials containing remnant of cytoplasmic organelles (black arrow). Bar $=5 \mu \mathrm{m}(\mathrm{A})$, intracytoplasmic electron lucent inclusion bodies containing cellular debris (blue arrows) $\mathrm{B} a r=2 \mu \mathrm{m}(\mathrm{B})$, two intracytoplasmic electron lucent bodies containing cellular debris (blue arrows). Bar= $10 \mu \mathrm{m}(\mathrm{C})$, dilated intercellular spaces (blue arrow) with shrunken of individual cell nucleus (black arrow). Bar=10 $\mu \mathrm{m}$ (D), Swollen cells with marked loss of cytoplasmic organelles (blue arrow) and chromatin condensation of the nucleus (red arrow). Other showing large intracytoplasmic electron lucent vacuole compressing nucleus (black arrow). $\mathrm{Bar}=2 \mu \mathrm{m}(\mathrm{E})$.

Table 1: The reagents of RT-qPCR mixture.

\begin{tabular}{ll} 
Reagents & Volume \\
\hline Viral RNA & $0.5 \mu \mathrm{L}$ \\
\hline Forward primer $(10 \mu \mathrm{M})$ & $1 \mu \mathrm{L}$ \\
backward primer $(10 \mu \mathrm{M})$ & $1 \mu \mathrm{L}$ \\
\hline SsoFast EvaGreen Supermix (Bio-Rad) & $5 \mu \mathrm{L}$ \\
$\begin{array}{l}\text { AMV reverse transcriptase }(200 \mathrm{U} / \mu \mathrm{L}) \\
\text { (Promega, Madison, WI, USA) }\end{array}$ & $0.2 \mu \mathrm{L}$ \\
$\begin{array}{ll}\text { nuclease free water (Invitrogen, Carlsbad, } \\
\text { CA, USA) }\end{array}$ & $\begin{array}{l}\text { added to a total } \\
\text { volume of } 10 \mu \mathrm{L}\end{array}$
\end{tabular}

Evidently, Newcastle and pox viruses are the major viruses that caused loses in pigeons either due to the high mortality by ND or by the culling due to skin lesions.
The predominant signs of the ND were typically nervous manifestations agreed with (Coudert and Donas, 2015; Marlier and Vindevogel, 2006) with Fairly high morbidity and mortality rate consistent with previous studies (Dolka et al., 2019; Wang et al., 2017) this may due to the flight habit of pigeon fanciers which help spread of disease among local lofts. According to Marlier and Vindevogel (2006). Symptoms may appear as persistent diarrhea without nervous manifestations but in our study, we couldn't rely on that due to the similarity with a lot of enteric diseases. Gross and microscopic lesions observed in this study were variable but the lesions in the brain were constant and agreed with previous studies (Dortmans et al., 2010; Liu et al., 2015; Dolka et al., 2019). Intracytoplasmic eosinophilic inclusion bodies and distinct accumulations of eosinophilic granular material were demonstrated in neurons of the nucleus reticularis in the brain stem and in Purkinje cells of chicken experimentally infected with PPMV-1 (Kommers et al., 2002). Chowdhary et al. (2020) reported marked histopathological changes in naturally infected pigeons in different body systems and organs like the respiratory system, enteric system, spleen, bursa of Fabricius, liver, kidneys and brain. Lesions in nervous tissue were more pronounced in pigeons affected with genotype II than in chicken affected with genotype XIII and represented focal gliosis, neuronal degeneration, satellitosis and neuronophagia (Chowdhary et al., 2020). Lungs in our findings showed necrotizing pneumonia with hyperplasia of bronchus associated lymphoid tissue. Faint cytoplasmic vacuolation and intracytoplasmic inclusions were also seen in some Purkinje cells of the cerebellum. Focal gliosis was observed in the cerebrum and cerebellum indicating demyelination of nerve tracts (Chowdhary et al., 2020). In this study, intracytoplasmic and intranuclear inclusions were identified in neurons by TEM of brain.

Table 2: The used cycling program of RT-qPCR was as follow.

\begin{tabular}{|ll}
\hline Cycles & Temperature and time \\
\hline One cycle & $50^{\circ} \mathrm{C}$ for $30 \mathrm{~min}$ \\
\hline Followed by one cycle & $95^{\circ} \mathrm{C}$ for $10 \mathrm{~min}$ \\
\hline 35 cycles & at $95^{\circ} \mathrm{C}$ for $10 \mathrm{~s}$ \\
& $60^{\circ} \mathrm{C}$ for $30 \mathrm{~s}$ \\
\hline
\end{tabular}

Table 3: The reagents of qPCR mixture.

\begin{tabular}{ll} 
Reagents & Volume \\
\hline Viral DNA & $0.5 \mu \mathrm{L}$ \\
\hline Forward primer $(10 \mu \mathrm{M})$ & $1 \mu \mathrm{L}$ \\
backward primer $(10 \mu \mathrm{M})$ & $1 \mu \mathrm{L}$ \\
SsoFast EvaGreen Supermix (Bio-Rad) & $5 \mu \mathrm{L}$ \\
nuclease free water (Invitrogen, Carlsbad, & added to a total \\
CA, USA) & volume of $10 \mu \mathrm{L}$
\end{tabular}


Table 4: The used cycling program of qPCR was as follow.

\begin{tabular}{|l|l|}
\hline Cycles & Temperature and time \\
\hline one cycle & $95^{\circ} \mathrm{C}$ for $2 \mathrm{~min}$ \\
\hline 35 cycles & at $95^{\circ} \mathrm{C}$ for $5 \mathrm{~s}$ \\
& $60^{\circ} \mathrm{C}$ for $30 \mathrm{~s}$
\end{tabular}

PMV1 was detected in pigeons by molecular techniques (Collins et al., 1989; Zanetti et al., 2001; Aldous et al., 2004). IHC showed positive staining for NDV in brain, lung, heart, intestine, liver, and kidney. Meanwhile, in previous study made by Carrasco et al. (2015), the liver and lung were negative in all examined birds. The use of IHC to detect APMV-1 infections in tissues of chickens has been reported several times (Brown et al., 1999; Lockaby et al., 1993). Large amounts of viruses were detected in the brain of one Pigeon at 10-day post infection (Kommers et al., 2002).

Using the negative staining technique (rapid preparation) for TEM, Catroxo et al. (2011) observed typical paramyxovirus particles in 45 (79\%) out of 57 stool samples from free-living pigeons (Columba livia) and Clavijo et al. (2000) observed avian paramyxovirus in allantoic fluid from specific pathogen free (SPF) chicken eggs inoculated with $10 \%$ tissue suspension (trachea, lung, brain, liver, or spleen.

Cutaneous lesions of PD were agreed with those observed by Audarya et al. (2018); Sudhakara and Sivajothi (2017); Immanni et al. (2014). Grossly, Sawale et al. (2019) reported vascular congestion with prominent ureter due to urate deposition in liver and kidneys of turkeys infected with turkey pox. However, Immanni et al. (2014) did not reveal any lesions of pathological significance internally in the upper respiratory and digestive tracts of infected pigeons. Histopathological examination of scab revealed hyperplasia of the epidermis and severe balloon degeneration with intracytoplasmic, eosinophilic inclusion bodies and sparse infiltration of inflammatory cells with the predominant population of heterophils (Sawale et al., 2019). Our histopathological findings in kidney and liver were partially coinciding with Sawale et al. (2019) who reported coagulative necrosis and swelling of tubular epithelium with narrowing of the lumen in kidney, severe vascular congestion in liver. Liver microscopical findings were marked congestion, perivascular and portal MNC infiltration besides hepatocytes necrosis. Massive heterophils and lymphocytes infiltration in liver was previously reported by Pandey et al. (2014) indicating secondarybacterialinfections.However,Pandey et al.(2014) observed more severe lung lesions including oedema with fibrin deposition in alveolar spaces and huge infiltration of heterophils in interstitial spaces. Although avipoxvirus was known to induce mild to moderate immunosuppression, the lesions found in other parenchymal organs were not specific for the disease Beytut and Haligür (2007) and might have been induced by an additional etiology as reported previously by Gerlach et al. (1998).

IHC for PCR confirmed cases was positive in cutaneous lesions as mentioned by Beytut and Haligür (2007) in chickens naturally infected with avipoxvirus.

Sawale et al. (2019) observed typical pox virus morphology having oval shaped structure with dumbbell shaped dense core (biconcave) by TEM made from slices of scab and similar findings were also reported earlier by Singh et al. (2003). Meanwhile, TEM of affected epidermal cells in our study showed swollen cells with intracytoplasmic electron lucent inclusion bodies containing virion particles, shrunken or pyknotic nuclei, marked loss of cytoplasmic organelles, dilated intracellular spaces and loss of intracellular adhesion. Similarly, Beytut and Haligür (2007) found numerous typical dumbbell-shaped poxvirus particles both within the cytoplasm of hyperplastic epithelial cells and in the inclusion bodies by TEM of affected chicken skin, consistent with other studies on various birds; wild red-legged partridges (Gortázar et al., 2002); short-toed larks (Calandrella rufescens) and Berthelot's pipits (Anthus berthelotti) (Smits et al., 2005) and quails (Gülbahar et al., 2005).

\section{CONCLUSIONS AND RECOMMENDATIONS}

This study presented clinical signs, postmortem, histopathological, immunohistochemical and ultrastructural changes in pigeons confirmed to be naturally infected with $\mathrm{ND}$ and PD by PCR. IHC showed positive staining for NDV in brain, lung, heart, intestine, liver, and kidney and showed positive staining for avipoxvirus in epidermis and dermis. TEM of infected brain tissue with NDV showed hypertrophied neuron having degenerated axon that lost its myelin sheath, intracytoplasmic and intranuclear electron dense inclusion bodies, numerous dilated mitochondria, and dilated RER. TEM of infected epidermal cells with avipoxvirus showed swollen cells with intracytoplasmic electron lucent inclusion bodies containing virion particles.

\section{NOVELTY STATEMENT}

Immunohistochemical and ultrastructural findings were investigated in naturally infected pigeons with ND. NDV positively stained by IHC in brain, lung, heart, intestine, liver, and kidney. Intracytoplasmic and intranuclear electron dense inclusion bodies were detected in infected brains of pigeons by TEM. 


\section{AUTHOR'S CONTRIBUTION}

Shady M. Shalaby: Clinical examination of infected pigeons, recording clinical signs and PM lesions, sample collection and shared in writing, submission and revision of the manuscript; Walaa F. Awadin: histopathological, immunohistochemical examination, shared in writing and revision of the manuscript; Mohamed F. Hamed: shared in writing and revision of the manuscript; Mohamed ElTholoth: running and interpreting PCR results; Iman Ibrahim: ultrastuctural examination and shared in writing manuscript; Ahmed F. El- Shaieb: put the plan of the work, supervise the whole techniques, shared in writing and revision of the manuscript.

\section{CONFLICT OF INTEREST}

The authors have declared no conflict of interest.

\section{REFERENCES}

-Aldous E,Fuller C,Mynn J,Alexander DJAP (2004).A molecular epidemiological investigation of isolates of the variant avian paramyxovirus type 1 virus (PPMV-1) responsible for the 1978 to present panzootic in pigeons. Avian Pathol. 33: 258269. https://doi.org/10.1080/0307945042000195768

-Alexander D, Russell P, Parsons G, Elzein EA, Ballouh A, Cernik K, Engstrom B, Fevereiro M, Fleury H, Guittet MJAP (1985). Antigenic and biological characterisation of avian paramyxovirus type I isolates from pigeons-an international collaborative study. Avian Pathol. 14: 365-376. https://doi.org/10.1080/03079458508436238

-Audarya S, Riyesh T, Kumar N, Chhabra D, Sikrodia R, Sharda R, Barua S, Garg UK (2018). Molecular diagnosis of a cutaneous form of pox in pigeons at mhow in Madhya Pradesh. Int. J. Curr. Microbiol. Appl. Sci., 7: 1318-1323. https://doi.org/10.20546/ijcmas.2018.709.157

- Baek HE, Bandivadekar RR, Pandit P, Mah M, Sehgal RNM, Tell LA (2020). TaqMan quantitative real-time PCR for detecting Avipoxvirus DNA in various sample types from hummingbirds. PLoS One, 15: e0230701. https://doi. org/10.1371/journal.pone.0230701

- BeytutE,Haligür M(2007).Pathological,immunohistochemical, and electron microscopic findings in the respiratory tract and skin of chickens naturally infected with avipoxvirus. Turk. J. Vet. Anim. Sci., 31: 311-317.

-Brown C, King D, Seal BJVP (1999). Pathogenesis of Newcastle disease in chickens experimentally infected with viruses of different virulence. Vet. Pathol. 36: 125-132. https://doi. org/10.1354/vp.36-2-125

-Bulbule N, Madale D, Meshram C, Pardeshi R, Chawak MJAAVS (2015). Virulence of newcastle disease virus and diagnostic challenges. Adv. Anim. Vet. Sci. 3: 14-21. https:// doi.org/10.14737/journal.aavs/2015/3.5s.14.21

- Carrasco A, Seki M, Mineo T, Peres J, Knychala L, Alves M, Benevenute J, Ikeda P, Pinto A (2015). Use of immunohistochemistry (IHC) in the detection of Newcastle disease virus (NDV) in experimentally and naturally infected birds. Afr.J. Microbiol. Res., Int.J. Morphol 9: 2225. https:// doi.org/10.5897/AJMR2015.7677
- Catroxo M, Martins A, Petrella S, Curi N, Melo NJIJM (2011). Research of viral agent in free-living pigeon feces (Columba livia) in the city of São Paulo, SP. Brazil Trans. Electron Micros., 29: 628-635. https://doi.org/10.4067/S071795022011000200055

- Chowdhary M, Nashiruddullah N, Abrol R, Sood S, Rahman S, Ahmed JA, Maqbool RJIJCMAS (2020). Newcastle disease and their pathology in fowls affected with genotype XIII and pigeons with genotype II. Int. J. Curr. Microbiol. App. Sci. 9: 3800-3810. https://doi.org/10.20546/ijcmas.2020.910.437

- Clavijo A, Robinson Y, Booth T, Munroe FJTCVJ (2000). Velogenic Newcastle disease in imported caged birds. The Canadian Vet. J. 41: 404.

- Collins M, Alexander D, Brockman S, Kemp P, Manvell RJAoV (1989). Evaluation of mouse monoclonal antibodies raised against an isolate of the variant avian paramyxovirus type 1 responsible for the current panzootic in pigeons. Archiv. Virol. 104: 53-61. https://doi.org/10.1007/BF01313807

- Coudert P, Donas E (2015). Maladies des pigeons: Prévention des épidémies et de la transmission à l'homme. Actualités Pharma., 54: 48-51. https://doi.org/10.1016/j. actpha.2014.11.027

-Docherty DE, Long RI, Flickinger EL, Locke LNJAD (1991). Isolation of poxvirus from debilitating cutaneous lesions on four immature grackles (Quiscalus sp.). Avian Dis. 35 (1):244-247. https://doi.org/10.2307/1591324

-Dolka B, Ledwoń A, Dolka I, Szeleszczuk P (2019). Evaluation of the pathogenicity of pigeon paramyxovirus type 1 isolated from racing pigeons. J. Comp. Pathol., 166: 140. https://doi. org/10.1016/j.jcpa.2018.10.127

-Doneley B (2006). Pigeon medicine and surgery. North Am. Vet. Conf., 20: 1525-1530.

-Dortmans JCFM, Fuller CM, Aldous EW, Rottier PJM, Peeters BPH (2010). Two genetically closely related pigeon paramyxovirus type 1 (PPMV-1) variants with identical velogenic fusion protein cleavage sites but with strongly contrasting virulence. Vet. Microbiol., 143: 139-144. https:// doi.org/10.1016/j.vetmic.2009.11.021

- Eisa M, Omer EJVR (1984). A natural outbreak of Newcastle disease in pigeons in the Sudan. Vet. Rec. 114(12): 297-297. https://doi.org/10.1136/vr.114.12.297

- Fenner F (2000). Adventures with poxviruses of vertebrates. FEMS Microbiol. Rev., 24: 123-133. https://doi. org/10.1111/j.1574-6976.2000.tb00536.x

- Gerlach H, Ramis A, Enders F, Casares M, Truyen U (1998). Avian pox in Lories (Neopsittacus sp.): A case report. Proc. Int. Virt. Conf. Vet. Med. Dis. Psit. Birds.

- Gortázar C, Millán J, Höfle U, Buenestado F, Villafuerte R, Kaleta E (2002). Pathology of avian pox in wild red-legged partridges (Alectoris rufa) in Spain. Ann.New York Acad. Sci. 969: 354-357. https://doi.org/10.1111/j.1749-6632.2002. tb04404.x

- Gülbahar MY, Çabalar M, Boynukara BJTJoV, Sciences A (2005). Avipoxvirus infection in quails. Turkish J. Vet. Anim. Sci. 29: 449-454.

- Guo H, Liu X, Xu Y, Han Z, Shao Y, Kong X, Liu S (2014). A comparative study of pigeons and chickens experimentally infected with PPMV-1 to determine antigenic relationships between PPMV-1 and NDV strains. Vet. Microbiol., 168: 88-97. https://doi.org/10.1016/j.vetmic.2013.11.002

-Immanni DH, Amaravathi P (2014). An out-break of cutaneous form of avian pox in pigeons (Columbia livia). Int. J. Sci. Environ. Technol., 3: 1484-1488. 
- Jan A, Ovais S, Shah S, Moona R, Asfar A (2017). Concurrent occurance of cutaneous and diptheric form of pigeon pox and it's successful amelioration with garlic and honey. Pharma Innovat. J. 6(12): 494-495.

- Kim SW, Roh J, Park CS (2016). Immunohistochemistry for pathologists: Protocols, pitfalls, and tips. J. Pathol. Transl. Med., 50: 411-418. https://doi.org/10.4132/ jptm.2016.08.08

- Kommers G, King D, Seal B, Carmichael K, Brown CJVP (2002). Pathogenesis of six pigeon-origin isolates of Newcastle disease virus for domestic chickens. Vet. Pathol. 39: 353-362. https://doi.org/10.1354/vp.39-3-353

- Liu M, Qu Y, Wang F, Liu S, Sun H (2015). Genotypic and pathotypic characterization of Newcastle disease virus isolated from racing pigeons in China. Poult. Sci., 94: 14761482. https://doi.org/10.3382/ps/pev106

- Lockaby S, Hoerr F, Ellis A, Yu MJAD (1993). Immunohistochemical detection of Newcastle disease virus in chickens. pp. 433-437. https://doi.org/10.2307/1591670

- Marlier D, Vindevogel H (2006). Viral infections in pigeons. Vet. J., 172: 40-51. https://doi.org/10.1016/j.tvj1.2005.02.026

-Mohan M, Fernandez TFJVW (2008). A case report of pigeon pox-histopathologic diagnosis. Vet. Biol. 1(4): 117.

- Morris JKJJcB (1965). A formaldehyde glutaraldehyde fixative of high osmolality for use in electron microscopy. Cell Biol. 27: 1A-149A.

-Pandey M, Ghosh R, Behera P, Gupta V, Tripathi S, Jolhe D, KshirsagarAA, Khan FFJIJVP (2014). Detection of Pox virus in domestic pigeon. Indian J. Vet. Pathol.38: 139-140. https://doi.org/10.5958/0973-970X.2014.01160.2

- Reynolds ESJJocb (1963). The use of lead citrate at high $\mathrm{pH}$ as an electron-opaque stain in electron microscopy. J. Cell Biol. 17: 208-212. https://doi.org/10.1083/jcb.17.1.208

- Sawale G, Lakshman MMHVB, Ramesh G (2019). Pathology of avipoxvirus in Turkey: Histopathology, cytology and electron microscopy study. Int. J. Livest. Res., pp. 1. https:// doi.org/10.5455/ijlr.20181009023808

- Singh A, Dash B, Kataria J, Dandapat S, Dhama KJIJoCMI, Diseases I (2003). Characterization of an Indian isolate of turkey pox virus. J. Comparat. Microbiol. Immunol. Infect. Dis. 24(2): 149-152. 24: 149.

-Slaoui M, Fiette L (2011). Histopathology procedures from tissue sampling to histopathological evaluation, Drug safety evaluation. Springer, pp. 69-82. https://doi. org/10.1007/978-1-60761-849-2_4
-Smits J, Tella JL, Carrete M, Serrano D, López GJVP (2005). An epizootic of avian pox in endemic short-toed larks (Calandrella rufescens) and Berthelot's pipits (Anthus berthelotti) in the Canary Islands, Spain. Vet. Pathol. 42: 59-65. https://doi.org/10.1354/vp.42-1-59

-Sudhakara RB, Sivajothi S (2017). Therapeutic management of cutaneous form of pox in pigeons with azithromycin. Int. J. Avian Wildlife Biol. 3(2): 136-137. https://doi. org/10.15406/ijawb.2018.03.00073

- Suvarna K, Layton C (2013). Bancroft's theory and practise of histological techniques ( $7^{\text {th }}$ edition) (Co-author).

-Tripathy D, Reed W (2003). In YM Saif, HJ Barnes, JR Glisson, AM Fadly, LR Mc-Dougald and DE Swayne (Eds.), Diseases of Poultry, $11^{\text {th }}$ edn Ames: Iowa State University Press. pp. 253Á269.

-Vindevogel H, Meulemans G, Halen P, Schyns P, Bourgueil P (1972). Sensibilité du pigeon voyageur adulte au virus de la maladie de newcastle. Annales de Recherches Vétérinaires, INRA Editions 3: 519-532.

-Wang X, Ren S, Wang X, Wang CY, Fan M, Jia Y, Gao X, Liu H, Xiao S, Yang Z (2017). Genomic characterization of a wild-bird-origin pigeon paramyxovirus type 1 (PPMV-1) first isolated in the northwest region of China. Arch. Virol., 162: 749-761. https://doi.org/10.1007/s00705-016-3156-5

-Wise MG, Suarez DL, Seal BS, Pedersen JC, Senne DA, King DJ, Kapczynski DR, Spackman E (2004). Development of a real-time reverse-transcription PCR for detection of newcastle disease virus RNA in clinical samples. J. Clin. Microbiol., 42: 329-338. https://doi.org/10.1128/ JCM.42.1.329-338.2004

-Xiang B, You R, Kang Y, Xie P, Zhu W, Sun M, Gao P, Li Y, Ren $T$ (2019). Host immune responses of pigeons infected with Newcastle disease viruses isolated from pigeons. Microbial. Pathog., 127: 131-137. https://doi.org/10.1016/j. micpath.2018.11.049

-Xue C, Xu X, Yin R, Qian J, Sun Y, Wang C, Ding C, Yu S, Hu S, Liu X, Cong Y, Ding Z (2017). Identification and pathotypical analysis of a novel VIk sub-genotype Newcastle disease virus obtained from pigeon in China. Virus Res., 238: 1-7. https://doi.org/10.1016/j.virusres.2017.05.011

-Zanetti F, Mattiello R, Garbino C, Kaloghlian A, Terrera MV, Boviez J, Palma E, Carrillo E, Berinstein AJAd (2001). Biological and molecular characterization of a pigeon paramyxovirus type- 1 isolate found in Argentina. Avian Dis. pp. 567-571. https://doi.org/10.2307/1592896 